Check for updates

Cite this: RSC Adv., 2019, 9, 20698

Received 9th April 2019

Accepted 22nd June 2019

DOI: 10.1039/c9ra02640a

rsc.li/rsc-advances

\section{Highly selective isomerization of cottonseed oil into conjugated linoleic acid catalyzed by multiwalled carbon nanotube supported ruthenium}

\author{
Shulai Liu, (D) *ab Bokai Yu, ${ }^{a}$ Zegao Wang, ${ }^{\text {de }}$ Jie Hu, ${ }^{a}$ Mingwen Fu, ${ }^{a}$ Yong Wang, ${ }^{f}$ \\ Jianhua Liu, (iD ${ }^{a}$ Zheng Guo, ${ }^{c}$ Xuebing $\mathrm{Xu}^{\text {cf }}$ and Yuting Ding ${ }^{\star a b}$
}

Supported ruthenium (Ru) has the capacity to catalyze the conjugation of double bonds in linoleic acid (LA) into conjugated linoleic acids (CLAs). It has been reported that CLAs have shown a lot of benefits to human health. To enhance the selectivity of cottonseed oil (CSO) to CLAs, various Ru catalysts supported by multiwalled carbon nanotubes (Ru/MWCNTs) were prepared using a microwave-heated ethylene glycol method. All catalysts were characterized by transmission electron microscopy (TEM), X-ray diffraction (XRD), X-ray photoelectron spectroscopy (XPS) and inductively coupled plasma optical emission spectrometry (ICP-OES). The catalytic efficiency/selectivity of Ru/MWCNTs and two commercially available $\mathrm{Ru}$ catalysts $\left(\mathrm{Ru} / \mathrm{C}\right.$ and $\mathrm{Ru} / \mathrm{Al}_{2} \mathrm{O}_{3}$ ) were investigated in a solvent-free system by catalyzing the isomerization of CSO. TEM analysis showed that Ru nanoparticles with average sizes of $1.0 \mathrm{~nm}$ to $1.8 \mathrm{~nm}$ were uniformly dispersed on the surface of the supports. Among the as-synthesized Ru/MWCNTs, catalyst S1 (diameter $<8 \mathrm{~nm}$, length $0.5-2 \mu \mathrm{m}$ ) and catalyst S4 (diameter $<8 \mathrm{~nm}$, length 10-30 $\mu \mathrm{m}$ ) exhibit excellent catalytic performance for isomerization of CSO with high yield of total CLA (15.91\% and $11.56 \%$, respectively) and high turnover frequency (TOF) of 10.39 and $11.38 \mathrm{~h}^{-1}$, which is much better than two typical commercial $\mathrm{Ru}$ catalysts $\left(\mathrm{Ru} / \mathrm{Al}_{2} \mathrm{O}_{3}\right.$ and $\left.\mathrm{Ru} / \mathrm{C}\right)$. It has been revealed that the average particle size and chemical state of Ru on the surface of MWCNTs have influence on the activity and selectivity of the isomerization reaction.

\section{Introduction}

Conjugated linoleic acids (CLAs) are a series of multiple positional $(7,9 ; 8,10 ; 9,11 ; 10,12 ; 11,13)$ and geometrical (cis and trans) isomers of linoleic acid (LA) containing conjugated double bonds. CLAs are widely found in meat and dairy products of ruminant animals, generated from ruminal biohydrogenation of LA. $^{1-3}$ However, only 20 CLAs have been reported in the 54 isomers of CLAs. ${ }^{4}$ Among these identified isomers of CLA, it has been proved that the most bioactive forms are cis-9, trans-11, trans-10 and cis-12. ${ }^{5}$ Recent studies have reported that CLA shows a variety of benefits in improving human health and biological

${ }^{a}$ Department of Food Science, Ocean College, Zhejiang University of Technology, Hangzhou 310014, China. E-mail: slliu@zjut.edu.cn; dingyt@zjut.edu.cn; Fax: +86571-88320237; Tel: +86-571-88320237

${ }^{b}$ Institute of Ocean Research, Zhejiang University of Technology, Hangzhou 310032, China

${ }^{c}$ Department of Engineering, Faculty of Science and Technology, Aarhus University, 8000 Aarhus C, Denmark

${ }^{d}$ College of Materials Science and Engineering, Sichuan University, Chengdu 610065, China

${ }^{e}$ Interdisciplinary Nanoscience Center, Aarhus University, 8000 Aarhus C, Denmark ${ }^{f}$ Wilmar (Shanghai) Biotechnology Research \& Development Center Co. Ltd, Area A, Shanghai 200137, China properties, such as anticancer activity, ${ }^{6}$ antiobesity effects, ${ }^{7-9}$ antiinflammatory properties, ${ }^{\mathbf{1 0}}$ antidiabetic effects, ${ }^{\mathbf{1 1}}$ cholesterol lowering ${ }^{12}$ and growth promoting. ${ }^{13}$

The main industrial approach to obtaining CLAs is converting LA and their alkyl esters into CLAs by using an alkaline catalyst. ${ }^{14-16}$ However, this isomerization process requires a great amount of reagents (alkali bases and solvents (e.g. DMSO)), therefore, lacks of ecological efficiency. Moreover, it is impossible to obtain the triglyceride form CLAs directly, and it has been reported that the fatty acids in triglyceride form are easily absorbed in intestine than fatty acid or ethyl ester. ${ }^{17,18}$

It is found that heterogeneous metal catalysts can facilitate the hydrogenation of double bond as well as catalyze the isomerization and double bond conjugation. ${ }^{\mathbf{1 5 , 1 6 , 1 9}}$ Compared with alkaline catalyzed isomerization, heterogeneous metal catalyzed isomerization has a variety of advantages. The process of the heterogeneous metal catalyst based isomerization does not result in a cleavage of ester bond, and the CLA-rich triglycerides can be obtained directly. ${ }^{20}$ Besides, the reaction can be carried out under a solvent-free system which can avoid the use of extra reagents. ${ }^{21}$ Furthermore, these solid metalcatalysts can be easily separated from the isomerized oil to be reused, and the recycling of the catalysts can thus makes a reduction of cost. 
So far a lot of metal catalysts have shown the potential to conjugate the unsaturated fatty acid. Among these catalysts, ruthenium based catalysts display a remarkable performance in the conjugation of LA. ${ }^{21-24}$ Besides, the nature of the supports is another important factor which affects the catalytic performance of metal catalysts. As reported in the literatures, a variety of materials (such as activated carbon, alumina and zeolite) have been used as supports for loading metals for LA isomerization to synthesize CLA. ${ }^{22,25-27}$ Most of the works in the literatures use LA and its esters as substrates, which can not obtain CLA-rich triglycerides by one step. Moreover, low selectivity of CLA is another drawback.

Above all, it's meaningful for industrial production of CLA to synthesize a better catalyst with high catalytic activity and high selectivity of bioactive CLA forms. Since the tubular carbon structures was first time observed by Iijima in $1991,{ }^{28}$ carbon nanotubes (CNTs) have been extensively studied. CNTs exhibited many excellent properties as a support in catalysis in many literatures, such as low corrosion, resistance to acid or alkali, high thermal (under inert atmospheres) and mechanical stability, possibility of affecting the activity and selectivity by tuning the specific metal-support interactions and lower cost compared with conventional supports like alumina or silica. ${ }^{29-32}$ Due to the excellent catalytic performance of CNTs, metal supported on catalysts were widely studied in many literatures. ${ }^{33,34}$

However, there is few literatures about carbon nanotubes catalysts used for LA isomerization into CLA. In this view, this work investigated the LA isomerization into CLA over ruthenium supported on multi-walled carbon nanotubes (MWCNTs) catalysts (Ru/MWCNTs). The ruthenium chloride hydrate and six MWCNTs with different length and diameter were used as catalyst precursors and supports to synthesize Ru/MWCNTs catalysts respectively. The synthesis of Ru/MWCNTs catalysts was carried out in ethylene glycol (EG) with the assistance of microwave heating. Besides, to better guide the industrial production of CLA, the refined cottonseed oil (CSO which contains about $55 \%$ of LA) was selected as the reaction substrate in this work, so that CLA-rich triglycerides can be obtained directly. To compare the catalytic performance with existing commercial catalysts, the synthesized Ru/MWCNTs catalysts were compared with two typically commercial catalysts, which are reported mostly in the literatures, and the results showed that excellent catalytic activity and selectivity in LA conjugation of CSO.

\section{Materials and methods}

\section{Materials}

Carboxylic MWCNTs was obtained from Dekedaojing Corporation (Beijing, China). Ruthenium chloride hydrate (35.0-42.0\% $\mathrm{Ru}$ basis) was purchased from Aladdin industrial Corporation (Shanghai, China). Ruthenium $5 \%$ on alumina $\left(\mathrm{Ru} / \mathrm{Al}_{2} \mathrm{O}_{3}\right)$ and ruthenium $5 \%$ on activated charcoal $(\mathrm{Ru} / \mathrm{C})$ were supplied by Sigma-Aldrich Co. (St. Louis, MO, USA). LA ( $\geq 99.0 \%$ purity based on GC analysis) was purchased from Aladdin industrial Corporation (Shanghai, China). Refined CSO was donated by Wilmar Biotechnology Research \& Development Center
(Shanghai) Co., Ltd (Shanghai, China). Boron trifluoridemethanol solution $\left(15 \% \mathrm{BF}_{3}\right.$ in methanol) and $n$-decane were purchased from Sigma-Aldrich Co. (St. Louis, MO, USA). All chemicals and solvents were of analytical grade.

\section{Synthesis of Ru/MWCNTs catalysts}

Ruthenium loading on all Ru/MWCNTs catalysts are theoretically 5\%. Typically, $0.2 \mathrm{~g}$ MWCNTs was added in $120 \mathrm{~mL}$ ethylene glycol. And the mixture was under sonication for $30 \mathrm{~min}$ to make sure MWCNTs are uniformly dispersed. After sonication, $3.0 \mathrm{~mL}$ of aqueous $\mathrm{RuCl}_{3} \cdot x \mathrm{H}_{2} \mathrm{O}$ solution was added dropwise with continuous stirring for $30 \mathrm{~min}$. And then the $1 \mathrm{~mol} \mathrm{~L}^{-1} \mathrm{NaOH}$ ethylene glycol solution was used to adjust the $\mathrm{pH}$ of the mixture to 4.0. Then, the solution was put in a microwave synthesis reactor to heated for $100 \mathrm{~s}(800 \mathrm{~W})$ after continuous stirring for $24 \mathrm{~h}$. The mixture solution was filtered, washed with deionized water until the $\mathrm{pH}$ of the filtrate reached the value 7.0 , and dried at $80{ }^{\circ} \mathrm{C}$ under vacuum overnight. The sample was ground to powder to use.

\section{Characterization}

Transmission electron microscope (TEM) images of samples were obtained by using a FEI Tecnai G2 F20. X-ray diffraction (XRD) of samples was obtained on a PNAlytical X' Pert PRO X-ray powder diffractometer, $\mathrm{Cu} \mathrm{K} \alpha$ radiation was employed and the working voltage and current were $60 \mathrm{kV}$ and $55 \mathrm{~mA}$, respectively. X-ray photoelectron spectroscopy (XPS) was performing using Kratos AXIS Ultra DLD with $\mathrm{Al} \mathrm{K} \alpha$ radiation. Inductively coupled plasma optical emission spectrometry (ICP-OES) was carried out on a SPECTRO ARCOS MV to obtain the content of ruthenium in catalysts.

\section{Isomerization reaction}

The reaction method was modified from the procedure of Liu et al. ${ }^{21}$ Isomerization of LA and CSO was carried out in a $10 \mathrm{~mL}$ pressure-resistant tube reactor (supplied by Sytracks Aps C/o, Interdisciplinary Nanoscience Center, Aarhus, Denmark) at $165^{\circ} \mathrm{C}$ (thermo-controlled by an oil-bath) with constant stirring $(800 \mathrm{rpm})$. In a typical experiment, $0.025 \mathrm{~g}$ catalyst and $1.0 \mathrm{~g}$ CSO were used. The reactor was loaded with the catalyst and the substrate followed by purging with nitrogen for $2 \mathrm{~min}$. The reaction reactor containing substrate and catalyst was then heated to the designated temperature with continuous magnetic stirring.

\section{GC-MS analysis of fatty acid composition}

The isomerized LA and CSO were methylated via alcoholysis in the presence of $0.5 \mathrm{~mol} \mathrm{~L}^{-1}$ methanolic $\mathrm{NaOH}$ solution for $5 \mathrm{~min}$ and $15 \% \mathrm{BF}_{3}$ in methanol for $2 \mathrm{~min}$ at $80{ }^{\circ} \mathrm{C}$. The resulting fatty acid methyl esters (FAME) were rinsed by saturated $\mathrm{NaCl}-\mathrm{K}_{2} \mathrm{CO}_{3}$ aqueous solution. The solution was then extracted with $n$-hexane, and the organic layer was dried over anhydrous $\mathrm{Na}_{2} \mathrm{SO}_{4}$. FAME compositions were analyzed by gas chromatography-mass spectrometer (GC-MS, Thermo Scientific, Shanghai, China) equipped with a fused silica capillary 
column ( $0.25 \mathrm{~mm}, 0.2 \mu \mathrm{m}, 100 \mathrm{~m}$, Supelco), using helium gas as

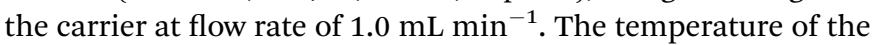
column was held at $170{ }^{\circ} \mathrm{C}$ for $1.0 \mathrm{~min}$; then increased to $195^{\circ} \mathrm{C}$ at the rate of $0.8{ }^{\circ} \mathrm{C} \mathrm{min}^{-1}$ and kept for $12 \mathrm{~min}$; followed by increasing at the rate of $5^{\circ} \mathrm{C} \min ^{-1}$ to $220^{\circ} \mathrm{C}$ and kept for $1 \mathrm{~min}$. The temperatures of the injector and the FID detector were set at $250{ }^{\circ} \mathrm{C}$. Area\% was converted to wt $\%$ using FID response factors described in AOCS Ce 1f-96, and then to mol\% calculated by being divided their corresponding molecular weights. In order to quantify the catalytic efficiency of the catalysts, the conversion of LA $\left(X_{\mathrm{LA}}\right)$ is used to denote the catalytic activity. To characterize the catalytic specificity towards different products, $S_{\mathrm{CLA}}, S_{c t}, S_{t t}$, were used to represent reaction selectivity towards the formation of total CLA, cis-9, trans-11- + trans-10, cis-12-CLA and trans-9, trans-11+trans-10, trans-12-CLA. $Y_{\text {CLA }}$ stands for the yield (content in product mixture) of total CLA. ${ }^{\mathbf{1 6}}$

$$
\begin{gathered}
X_{\mathrm{LA}}=\frac{\mathrm{LA}_{0}-\mathrm{LA}_{1}}{\mathrm{LA}_{0}} \\
Y_{\mathrm{CLA}}=\mathrm{CLA}_{1}-\mathrm{CLA}_{0} \\
S_{\mathrm{CLA}}=\frac{\mathrm{CLA}_{1}-\mathrm{CLA}_{0}}{\mathrm{LA}_{0}-\mathrm{LA}_{1}} \\
S_{c t}=\frac{(c, t-\mathrm{CLA})_{1}-(c, t-\mathrm{CLA})_{0}}{\mathrm{LA}_{0}-\mathrm{LA}_{1}} \\
S_{t t}=\frac{(t, t-\mathrm{CLA})_{1}-(t, t-\mathrm{CLA})_{0}}{\mathrm{LA}_{0}-\mathrm{LA}_{1}}
\end{gathered}
$$

where $\mathrm{LA}_{0} ; \mathrm{CLA}_{0} ;(c, t \text {-CLA })_{0} ;(t, t \text {-CLA })_{0}$ represent the content (\%) of LA; total CLA; $c, t$-CLA (cis-9, trans-11- + trans-10, cis-12-CLA); t,t-CLA (trans-9, trans-11- + trans-10, trans-12-CLA) in CSO. LA ; $\mathrm{CLA}_{1} ;(c, t-\mathrm{CLA})_{1} ;(t, t-\mathrm{LA})_{1}$ represent the content (\%) of LA; total CLA; c,t-CLA (cis-9, trans-11- + trans-10, cis-12-CLA); t,t-CLA (trans-9, trans-11- + trans-10, trans-12-CLA) in conjugated products of CSO.

\section{Results and discussion}

\section{Characterization of Ru/MWCNTs catalysts}

Since the surface of MWCNTs is hydrophobic, they tend to aggregate in polar solvent. And the MWCNTs modified by functional groups can provide enough defects to make ruthenium nanoparticles uniformly distribute on its surface of MWCNTs. In this work, MWCNTs modified with carboxyl (shown in Table 1) with different length and diameter were

Table 1 The properties of six types of MWCNTs supports

\begin{tabular}{lllll}
\hline MWCNTs & Diameter $(\mathrm{nm})$ & $\begin{array}{l}\text { Length } \\
(\mu \mathrm{m})\end{array}$ & $\begin{array}{l}\text { Specific surface } \\
\text { area }\left(\mathrm{m}^{2} \mathrm{~g}^{-1}\right)\end{array}$ & $\begin{array}{l}-\mathrm{COOH} \\
(\mathrm{wt} \%)\end{array}$ \\
\hline 1 & $<8$ & $0.5-2$ & $>500$ & 3.86 \\
2 & $10-20$ & $0.5-2$ & $>200$ & 3.86 \\
3 & $>50$ & $0.5-2$ & $>40$ & 3.86 \\
4 & $<8$ & $10-30$ & $>500$ & 3.86 \\
5 & $10-20$ & $10-30$ & $>200$ & 3.86 \\
6 & $>50$ & $10-30$ & $>40$ & 3.86
\end{tabular}

chosen as the supports. The corresponding catalysts are represented as S1, S2, S3, S4, S5 and S6. The MWCNTs supported Ru nanoparticles (NPs) were prepared by a microwave-heated polyol process. It has been agreed by a large number of studies that the microwave-heated polyol process is an efficient way to prepare polymer stabilized metal nanoparticles. ${ }^{35-38}$ The synthesis process is shown in Fig. 1.

Transmission electron microscopy (TEM) analysis reveals that the Ru NPs in the Ru/MWCNTs catalysts (Fig. 2) uniformly dispersed on the surface of the supports and have a narrow distribution in average size of 1.0 to $1.8 \mathrm{~nm}$. The particle size distribution are estimated based on 200 particles selected randomly for each catalyst. It is generally agreed that the rate of reduction of the metal precursor determines the size of metal NPs. Due to the high dielectric constant (41.4 at $298 \mathrm{~K}$ ) and the dielectric loss of ethylene glycol, the rapid heating can occur easily under microwave irradiation. Fast heating rates can accelerate the formation of the metal NPs, and the uniform microwave irradiation provides more homogeneous circumstances for their nucleation growth. Fig. 2 also shows that the average $\mathrm{Ru}$ particle sizes of $\mathrm{Ru} / \mathrm{Al}_{2} \mathrm{O}_{3}$ and $\mathrm{Ru} / \mathrm{C}$ are $1.4 \mathrm{~nm}$ and $1.2 \mathrm{~nm}$, respectively.

Fig. 3 shows XRD patterns of raw materials of MWCNTs (a) and $\mathrm{Ru} / \mathrm{MWCNTs}$ catalysts (b). The raw materials of MWCNTs exhibits 3 peaks at $26.0^{\circ}, 43.0^{\circ}$ and $44.5^{\circ}$, corresponding to the (002), (100), and (101) planes of graphite, ${ }^{39}$ respectively. Intriguingly, there is no obvious difference between the Fig. 3(a) and (b), which means that the diffraction signals related to the $\mathrm{Ru}$ species can not be observed from XRD. This phenomenon confirms that ruthenium has a good deposition on the surface of MWCNTs. Besides, the TEM results show that the average size of Ru NPs is less than $1.8 \mathrm{~nm}(1.0-1.8 \mathrm{~nm})$. It is generally believed that the XRD diffraction peak broadens with the decrease of the nanoparticle size. Moreover, when the size of Ru crystallites is lower than the limitation of XRD detection, the diffraction peak cannot be observed. The result of XRD is consistent with the TEM results.

$\mathrm{X}$-ray photoelectron spectroscopy (XPS) is generally used to identify the composition and chemical states of the components on the surface of materials. ${ }^{40}$ In order to observe and analyze the oxidation states and content of ruthenium in the catalysts, the XPS analysis is performed for different $\mathrm{Ru}$ / MWCNTs catalysts. It can be obviously seen from Fig. 4 that the dominant composing elements are $\mathrm{C}, \mathrm{O}$ and $\mathrm{Ru}$ for six $\mathrm{Ru} /$ MWCNTs catalysts. The two characteristic B.E. peaks at around $483-487 \mathrm{eV}$ and $461-467 \mathrm{eV}$ are contributed to $3 \mathrm{p}_{1 / 2}$ and $3 \mathrm{p}_{3 / 2}$,
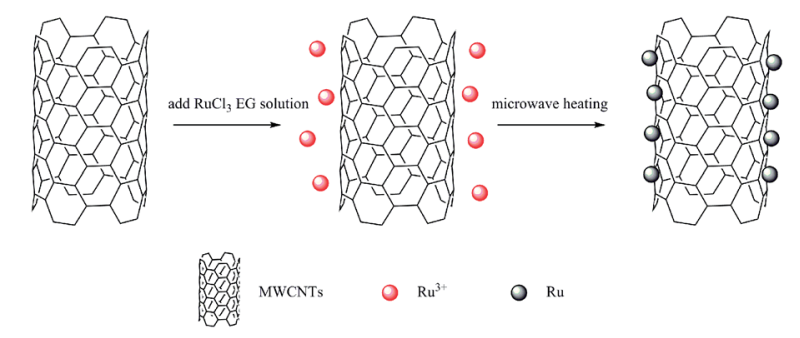

Fig. 1 Synthesis process of Ru/MWCNTs catalysts. 

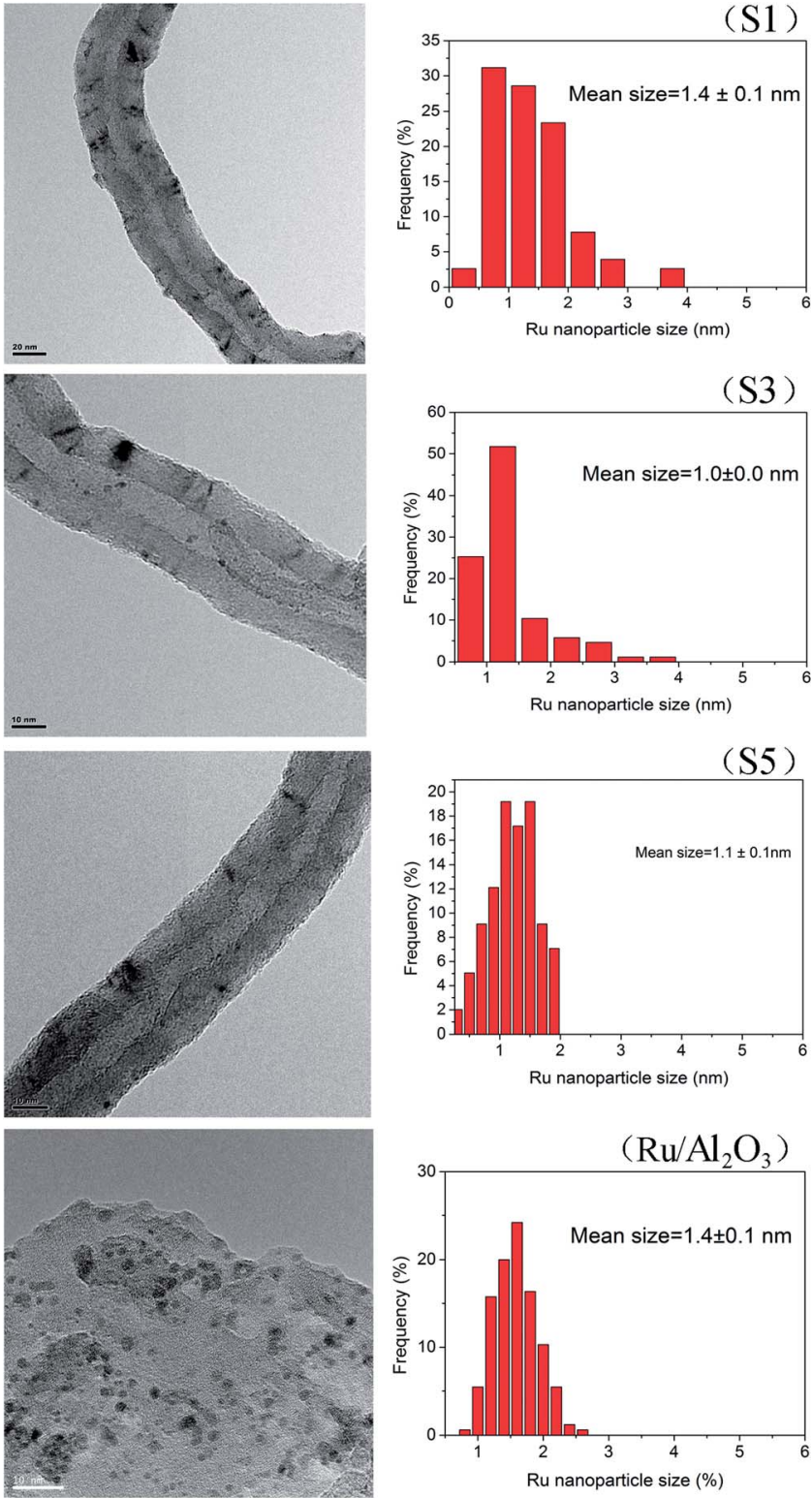
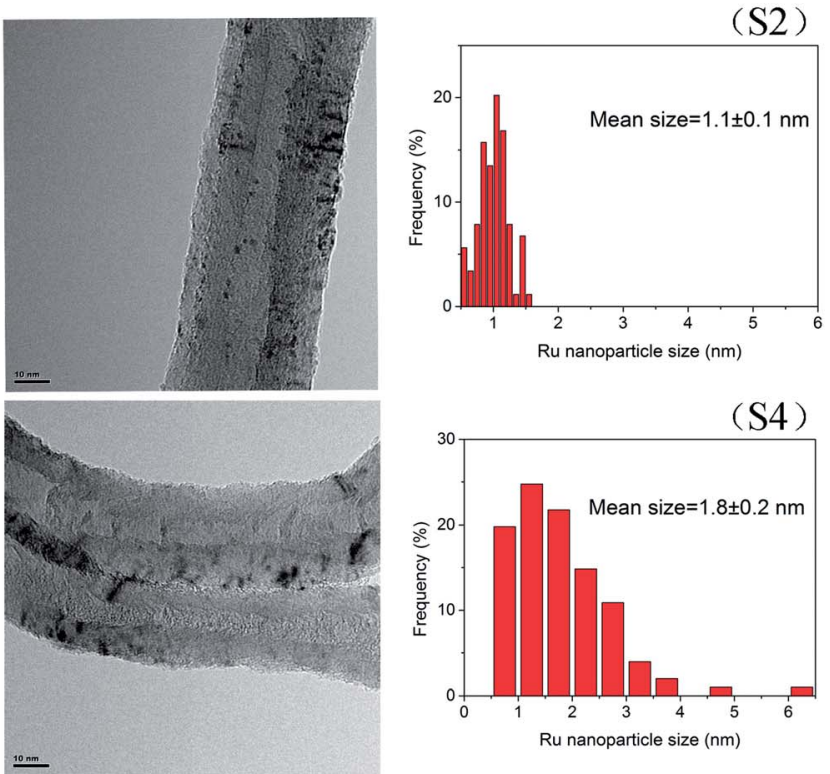

(S4)
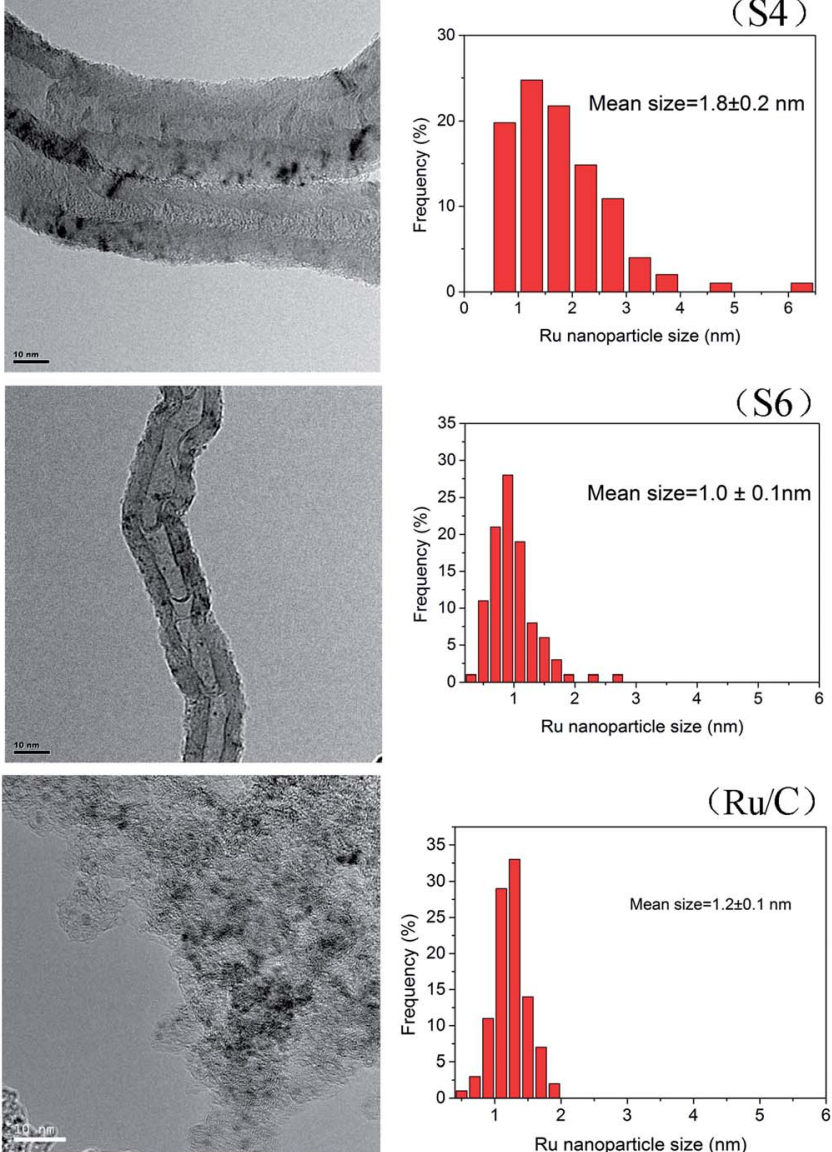

Fig. 2 TEM images and crystal size distribution of different Ru/MWCNTs catalysts and two commercial Ru catalysts.

respectively. The $\mathrm{C} 1 \mathrm{~s}$ peak is overlapped with $\mathrm{Ru} 3 \mathrm{~d}$ peak at around $284 \mathrm{eV}$. To obtain the information of $\mathrm{Ru}$ oxidation states, we have performed the deconvolution of 3p peaks (Fig. 5, calibrated by C 1 s) by with $80 \%$ Gaussian and $20 \%$ Lorentzian fitting. To avoid the interference from carbon substrate the
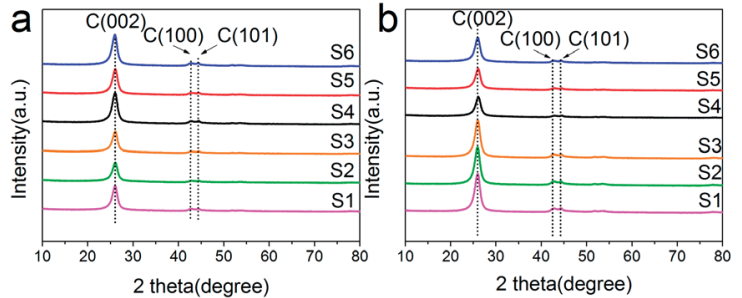

Fig. 3 XRD patterns of MWCNTs supports (a) and Ru/MWCNTs catalysts (b). deconvolution of $3 \mathrm{~d}$ spectra is not performed (Fig. 6). ${ }^{41}$ For comparison purpose, all peaks are deconvoluted into two components: $\mathrm{RuO}_{2}(\mathrm{IV})$ and $\mathrm{Ru}(0)$. The detailed analysis results of atomic composition and Ru oxidation state are shown in Table 2. Besides, the signal of Ru 3p of S2 catalyst from Fig. 5(b) is not observed, which might be due to the content of $\mathrm{Ru}$ is lower than the limitation of XPS. As shown from Table 2, the atomic ratio of $\mathrm{Ru}$ ranges from $0.18 \%$ to $0.58 \%$; and the different ruthenium loading of six Ru/MWCNTs catalysts may contribute to the physical properties (diameter and length) of the support are different, which may influence the reduction of ruthenium nanoparticles. Moreover, it can be found that the atomic ratio of ruthenium of S1 catalysts is higher than S2 and S3 catalysts which has the same length $(0.5-2 \mu \mathrm{m})$ but different diameter $(\mathrm{S} 1<8 \mathrm{~nm}, \mathrm{~S} 210-20 \mathrm{~nm}, \mathrm{~S} 3>50 \mathrm{~nm})$; and this phenomenon also can be seen in S4, S5, S6 catalysts whose 

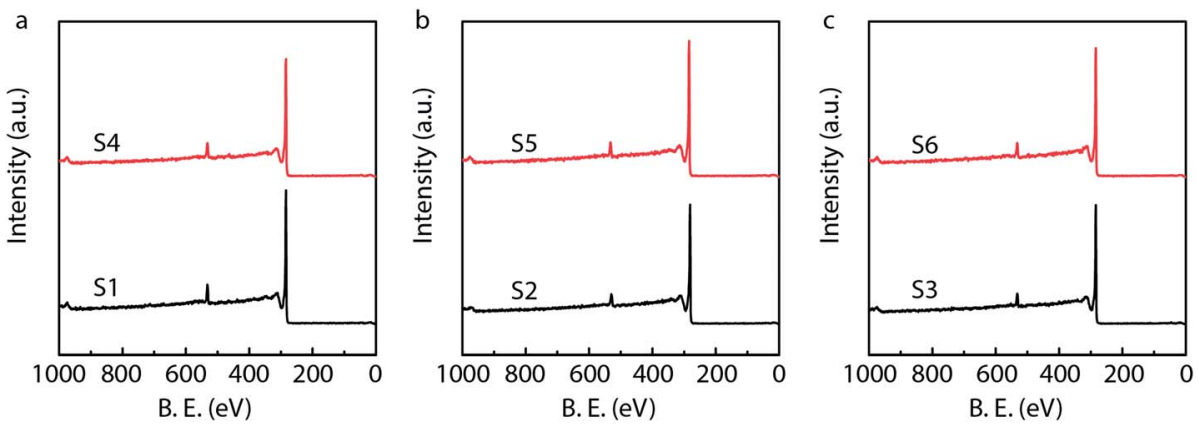

Fig. 4 XPS spectra of different Ru/MWCNTs catalysts.

length is $10-30 \mu \mathrm{m}$. To obtain the $\mathrm{Ru}$ content of different catalysts, the ICP-OES was performed (shown in Table 2). The ICP-OES results show that the ruthenium contents for S1 to S6 catalyst are $2.8 \%, 1.1 \%, 2.0 \%, 1.9 \%, 1.5 \%, 1.6 \%$ respectively, and $\mathrm{Ru} / \mathrm{Al}_{2} \mathrm{O}_{3}$ and $\mathrm{Ru} / \mathrm{C}$ are $4.9 \%$ and $4.9 \%$ respectively.

\section{Isomerization reaction results of cottonseed oil with $\mathrm{Ru} /$ MWCNTs catalysts}

In current work we choose two typical commercial catalysts $(\mathrm{Ru} /$ $\mathrm{Al}_{2} \mathrm{O}_{3}$ and $\mathrm{Ru} / \mathrm{C}$ ) to isomerize CSO for comparison. The isomerization reaction results are shown in Table 3. According to previous work, $165{ }^{\circ} \mathrm{C}$ was chosen as the reaction temperature and $800 \mathrm{rpm}$ stirring rate is used to assure the catalysts disperse uniformly in the substrate. ${ }^{21}$

As seen from Table 3, the conversion of LA in CSO $\left(X_{\mathrm{LA}}\right)$ of six $\mathrm{Ru} / \mathrm{MWCNTs}$ catalysts (S1 to S6) ranges from $7.93 \%$ to $37.66 \%$; the yield of total CLA ( $Y_{\text {CLA }}$ ) of six Ru/MWCNTs ranges from $2.25 \%$ to $15.91 \%$. Especially, sample 1 (S1) shows the best catalytic activity both in $X_{\mathrm{LA}}(37.66 \%)$ and $Y_{\mathrm{CLA}}(15.91 \%)$; which is much higher than $\mathrm{Ru} / \mathrm{Al}_{2} \mathrm{O}_{3}\left(X_{\mathrm{LA}} 5.57 \%\right.$ and $\left.Y_{\mathrm{CLA}} 1.95 \%\right)$ and $\mathrm{Ru} / \mathrm{C}\left(X_{\mathrm{LA}} 14.21 \%\right.$ and $\left.Y_{\mathrm{CLA}} 5.82 \%\right)$. The selectivity towards CLA $\left(S_{\text {CLA }}\right)$ and selectivity towards cis-9, trans-11- and 10-trans, cis-12CLAs $\left(S_{c t}\right)$ of six Ru/MWCNTs are $49.56-74.34 \%$ and $44.05-$ $65.63 \%$, respectively. Except S5 ( $S_{\text {CLA }} 49.56 \%$ and $\left.S_{c t} 44.05 \%\right)$, the selectivity towards CLA and the selectivity towards cis-9, trans-11- and 10-trans, cis-12-CLA of Ru/MWCNTs catalysts are higher than $\mathrm{Ru} / \mathrm{Al}_{2} \mathrm{O}_{3}\left(S_{\text {CLA }} 61.13 \%\right.$ and $\left.S_{c t} 52.98 \%\right)$. Compared with $\mathrm{Ru} / \mathrm{C}\left(S_{\mathrm{CLA}} 71.50 \%\right.$ and $\left.S_{c t} 62.65 \%\right)$, there is no significant difference in $S_{\mathrm{CLA}}$ and $S_{c t}$ of Ru/MWCNTs (except S5).

The nature of the support materials and the redox states of the metal are known to influence the chemisorptive and affect the catalytic properties of metal catalyst. ${ }^{42}$ Combine the XPS and the isomerization reaction result, it can be found that the ratio of $\mathrm{Ru}(0)$ and $\mathrm{Ru}(\mathrm{Iv})$ of $\mathrm{S} 1(\mathrm{Ru}(0) 49 \%$ and $\mathrm{Ru}(\mathrm{Iv}) 51 \%)$ and $\mathrm{S} 4$ $\left(\mathrm{Ru}(0) 51 \%\right.$ and $\mathrm{Ru}(\mathrm{Iv})$ 49\%), which have higher $Y_{\mathrm{CLA}}$, is more closer to $1: 1$. It also can be seen from other catalysts including S3 ( $\mathrm{Ru}(0) 53 \%$ and $\mathrm{Ru}(\mathrm{Iv})$ 47\%), S5 (Ru(0) $47 \%$ and $\mathrm{Ru}(\mathrm{Iv}) 53 \%)$, $\mathrm{S} 6 \mathrm{Ru}(0) 48 \%$ and $\mathrm{Ru}(\mathrm{Iv}) 52 \%), \mathrm{Ru} / \mathrm{Al}_{2} \mathrm{O}_{3}(\mathrm{Ru}(0) 44 \%$ and $\mathrm{Ru}(\mathrm{Iv})$ $56 \%)$ and $\mathrm{Ru} / \mathrm{C}(\mathrm{Ru}(0) 53 \%$ and $\mathrm{Ru}(\mathrm{Iv}) 47 \%)$ when the ratio of $\mathrm{Ru}(0)$ and $\mathrm{Ru}(\mathrm{Iv})$ is far away from $1: 1$, the $Y_{\mathrm{CLA}}$ decreases. And the $\mathrm{S} 3$ and $\mathrm{Ru} / \mathrm{C}$ with same ratio of $\mathrm{Ru}(0)$ and $\mathrm{Ru}(\mathrm{Iv})$ show the similar isomerization result. All the Ru/MWCNTs exhibited better catalytic performance than $\mathrm{Ru} / \mathrm{C}$ and $\mathrm{Ru} / \mathrm{Al}_{2} \mathrm{O}_{3}$, this can be contributed to metal-support interaction. As literaures reported, ${ }^{43}$ the MWCNTs can transfer electron to Ru which can increase the chance of substrate and metal contact to obtain better catalytic activity.

The isomerization process of LA into CLA can be explained by the Horiuti-Polanyi mechanism, which describes hydrogenation and isomerization of olefins. As shown in Fig. 7, there are several steps: (a) linoleic acid is chemisorbed on the $\mathrm{Ru}$ surface. (b) A hydrogen atom desorbs from Ru surface formatting a half-hydrogenated intermediate. (c) The formation of a saturated bond or (d) Abstraction of a neighbouring hydrogen leading to the formation of a di-adsorbed complex. (e) The desorption of the geometrical and/or positional isomer. When the adsorbed hydrogen on the Ru surface is high, the hydrogenation of half-hydrogenated intermediate will happen (step (c)). In this work, the catalysts were not preactivated by $\mathrm{H}_{2}$ making the adsorbed hydrogen on the Ru surface is low, making reaction trend to isomerization not hydrogenation. Furthermore, due to the electron-donor property of MWCNTs,
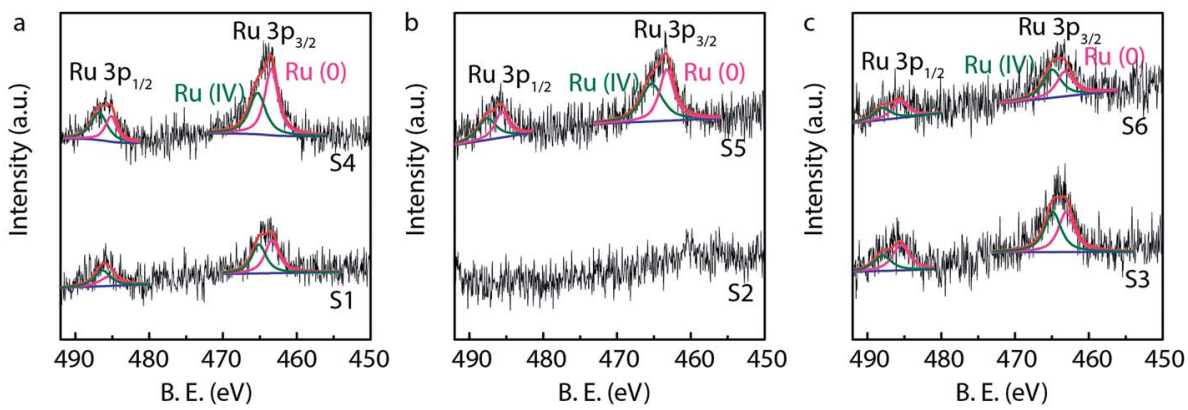

Fig. 5 High resolution Ru 3p XPS spectra of Ru/MWCNTs catalysts with analysis of oxidation states and atomic ratio of Ru. 

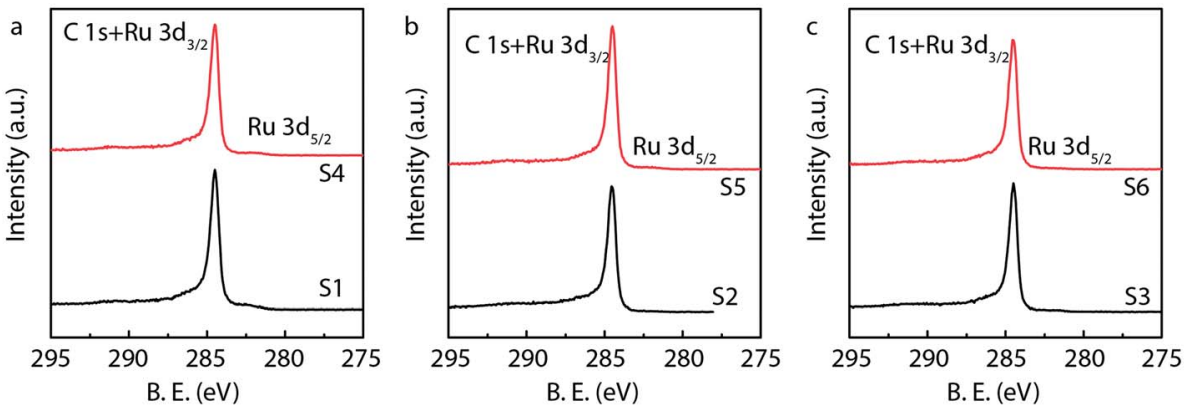

Fig. 6 High resolution C 1s and Ru 3d XPS spectra of Ru/MWCNTs catalysts.

Table 2 Spectral parameters for XPS of different supported Ru catalysts

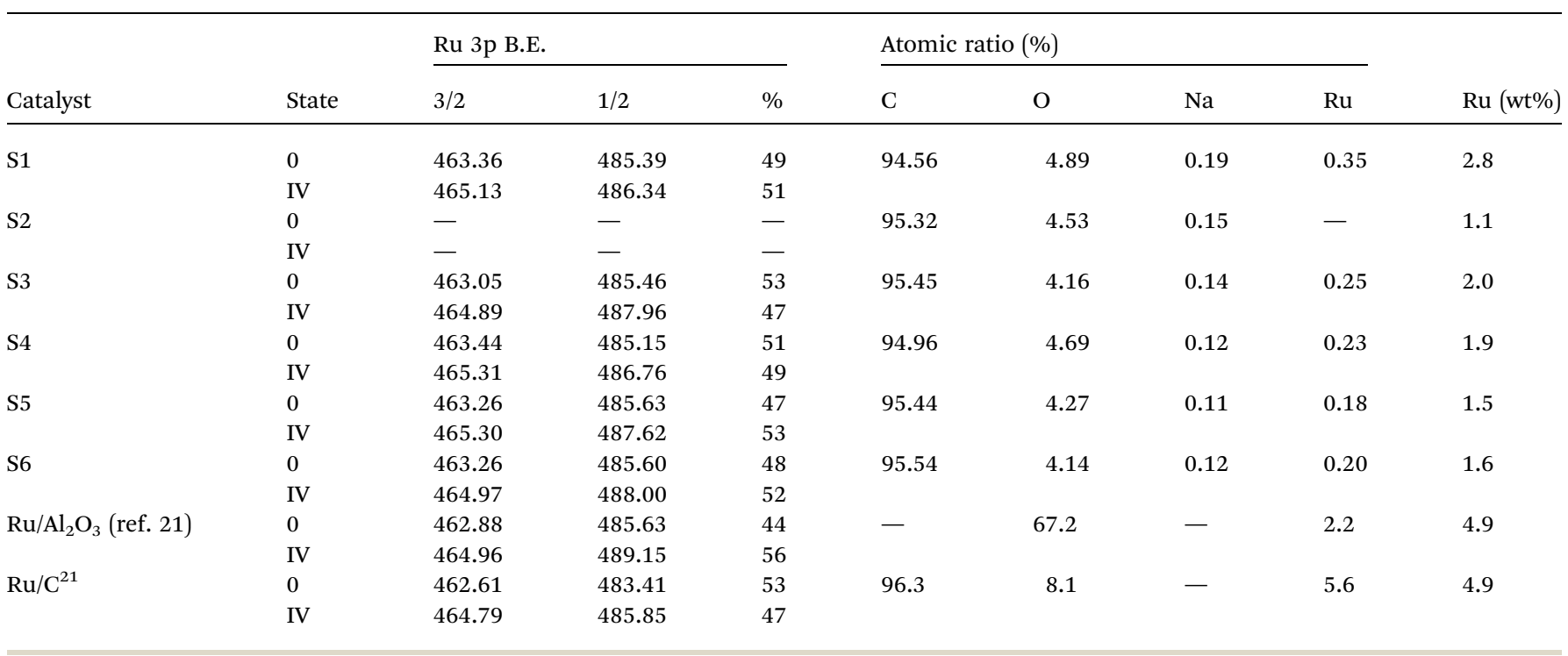

there is a metal-support interaction between Ru nanoparticles and MWCNTs, which prevents the re-oxidation of $\mathrm{Ru}$ and increases the chance of linoleic acid and Ru contact to obtain better conjugation results. ${ }^{43}$ This can be used for the explanation of why all the $\mathrm{Ru} / \mathrm{WMCNTs}$ exhibited better catalytic performance than $\mathrm{Ru} / \mathrm{C}$ and $\mathrm{Ru} / \mathrm{Al}_{2} \mathrm{O}_{3}$.

To compare the catalytic properties over different catalysts, the calculation results of the number of moles of ruthenium in catalysts (in $25 \mathrm{mg}$ catalyst), conversion of $\mathrm{LA}\left(X_{\mathrm{LA}}\right)$ and turnover

Table 3 Selectivity in linoleic acid of cottonseed oil isomerization over different catalysts ${ }^{a}$

\begin{tabular}{llrrlrr}
\hline Catalyst & $T\left({ }^{\circ} \mathrm{C}\right)$ & $Y_{\text {CLA }}(\%)$ & $X_{\text {LA }}(\%)$ & $S_{\text {CLA }}(\%)$ & $S_{c t}(\%)$ & $S_{t t}(\%)$ \\
\hline S1 & 165 & 15.91 & 37.66 & 73.76 & 59.02 & 14.74 \\
S2 & 165 & 5.23 & 12.80 & 71.35 & 63.17 & 8.19 \\
S3 & 165 & 6.23 & 14.63 & 74.34 & 65.63 & 8.71 \\
S4 & 165 & 11.56 & 28.53 & 70.75 & 58.75 & 12.00 \\
S5 & 165 & 2.25 & 7.93 & 49.56 & 44.05 & 5.51 \\
$\mathrm{~S} 6$ & 165 & 6.99 & 17.84 & 68.40 & 59.20 & 9.20 \\
$\mathrm{Ru} / \mathrm{Al}_{2} \mathrm{O}_{3}$ & 165 & 1.95 & 5.57 & 61.13 & 52.98 & 8.15 \\
$\mathrm{Ru} / \mathrm{C}$ & 165 & 5.82 & 14.21 & 71.50 & 62.65 & 8.85
\end{tabular}

${ }^{a}$ Reaction conditions: substrate load, $1 \mathrm{~g}$ of cottonseed oil; reaction time: $8 \mathrm{~h}$; catalyst load, $0.025 \mathrm{~g}$. frequency of CLA $\left(\mathrm{TOF}_{\mathrm{CLA}}\right)$ were shown in Table 4 . Among the remaining seven catalysts, sorting results by $\mathrm{TOF}_{\mathrm{CLA}}$ is $\mathrm{S} 4>\mathrm{S} 1>$ $\mathrm{S} 3>\mathrm{S} 5>\mathrm{S} 6>\mathrm{Ru} / \mathrm{C}>\mathrm{Ru} / \mathrm{Al}_{2} \mathrm{O}_{3}$. Besides, the $\mathrm{TOF}_{\mathrm{CLA}}$ of sample 4 $\left(11.38 \mathrm{~h}^{-1}\right)$ and sample $1\left(10.39 \mathrm{~h}^{-1}\right)$ are much higher than two commercial catalysts $\left(\mathrm{Ru} / \mathrm{Al}_{2} \mathrm{O}_{3} 0.72 \mathrm{~h}^{-1}\right.$ and $\left.\mathrm{Ru} / \mathrm{C} 2.14 \mathrm{~h}^{-1}\right)$. In addition to high TOF of S1 and S4 catalysts, $X_{\mathrm{LA}}$ of S1 (21.57\%) and $\mathrm{S} 4(16.34 \%)$ is also much higher than other catalysts. Compared with other catalysts, the supports of S1 catalyst and S4 catalyst have bigger specific surface area (shown in Table 1). As literatures said, higher specific surface area may supports more active sites which can increase catalytic activity. ${ }^{44-46}$ Although the TOF $\mathrm{CLA}_{\mathrm{CA}}$ of $\mathrm{S} 2$ with low ruthenium loading is up to $8.76 \mathrm{~h}^{-1}$, the $Y_{\mathrm{CLA}}$ and $X_{\mathrm{LA}}$ are just $5.23 \%$ and $7.33 \%$ respectively. Furthermore, if the left several samples were sorting by average size, the order is $\mathrm{S} 4(1.8 \mathrm{~nm})>\mathrm{S} 1(1.4 \mathrm{~nm})>\mathrm{S} 3(1.3 \mathrm{~nm})$ $>\mathrm{S} 5(1.1 \mathrm{~nm})>\mathrm{S} 6(1.0 \mathrm{~nm})$, which is well consistent with TOF sort result; and from this result, the size of Ru nanoparticles may influence the TOF of the reaction.

In selectivity aspect (data was shown in Table 3), it is found that high $X_{\mathrm{LA}}$ is always with high yield of CLA $\left(Y_{\mathrm{CLA}}\right)$ and high selectivity of trans, trans-CLA $\left(S_{t t}\right)$. This is due to the consumption of LA is a second-order reaction and that the rate of consumption of LA depends on the concentration of LA present in the reaction system, and the formation of trans, trans-CLA is 


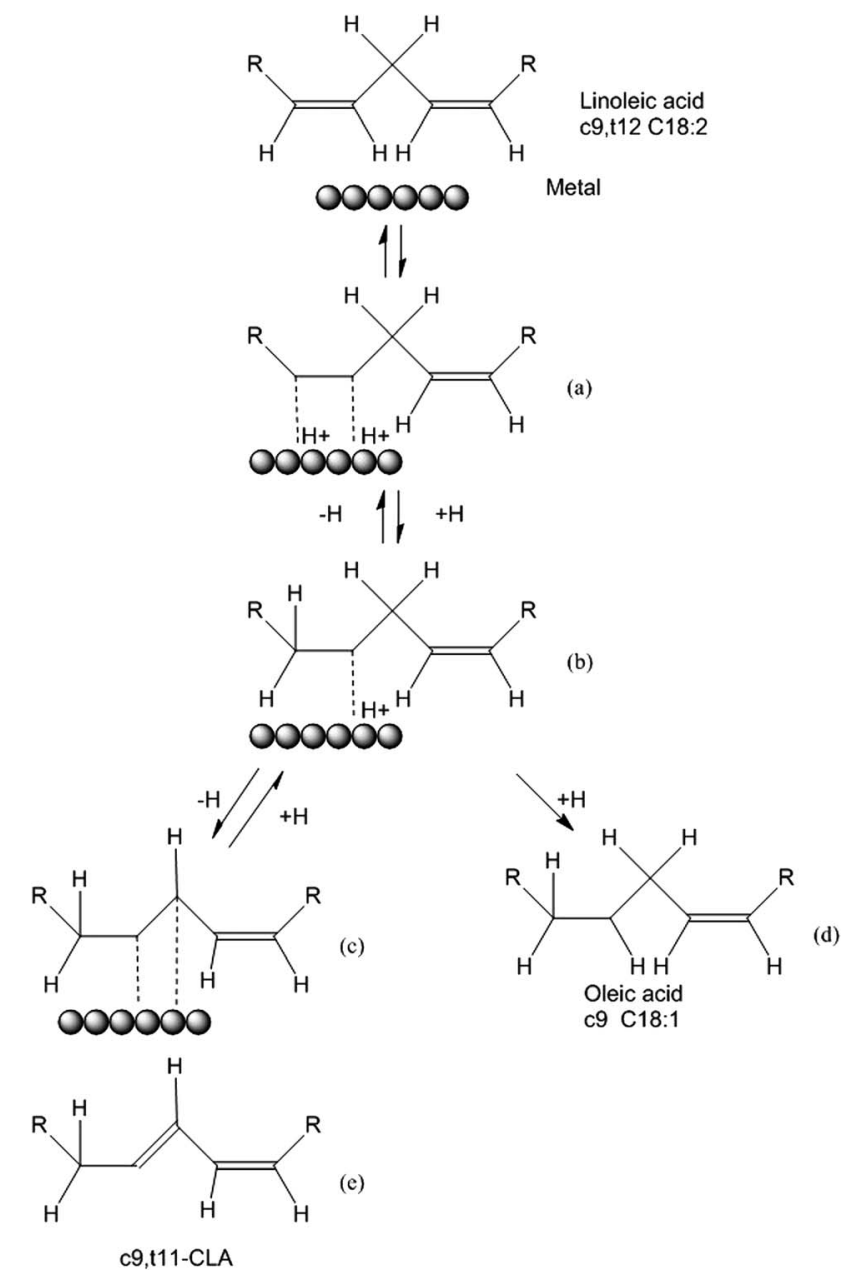

Fig. 7 Horiuti-Polanyi mechanism of the isomerization and hydrogenation of linoleic acid.

Table 4 Comparison of different catalysts for linoleic acid conjugation

\begin{tabular}{lrlrl}
\hline Catalyst & $Y_{\mathrm{CLA}}(\%)$ & $n_{\mathrm{Ru}}(\mathrm{mol})$ & $X_{\mathrm{LA}}(\%)$ & $\mathrm{TOF}_{\mathrm{CLA}}{ }^{a}\left(\mathrm{~h}^{-1}\right)$ \\
\hline $\mathrm{S} 1$ & 15.91 & $6.98 \times 10^{-6}$ & 21.57 & 10.39 \\
$\mathrm{~S} 2$ & 5.23 & $2.72 \times 10^{-6}$ & 7.33 & 8.76 \\
$\mathrm{~S} 3$ & 6.23 & $5.05 \times 10^{-6}$ & 8.28 & 5.62 \\
$\mathrm{~S} 4$ & 11.56 & $4.63 \times 10^{-6}$ & 16.34 & 11.38 \\
$\mathrm{~S} 5$ & 2.25 & $3.64 \times 10^{-6}$ & 4.54 & 2.81 \\
$\mathrm{~S} 6$ & 6.99 & $1.14 \times 10^{-6}$ & 10.22 & 2.79 \\
$\mathrm{Ru} / \mathrm{Al}_{2} \mathrm{O}_{3}$ & 1.95 & $1.24 \times 10^{-5}$ & 3.19 & 0.72 \\
$\mathrm{Ru} / \mathrm{C}$ & 5.82 & $1.24 \times 10^{-5}$ & 8.14 & 2.14
\end{tabular}

${ }^{a} \mathrm{TOF}_{\mathrm{CLA}}=$ mole of total CLA/(moles of surface $\mathrm{Ru} \times$ reaction times). Moles of surface Ru was calculated.

governed by thermodynamics. ${ }^{47,48}$ Though there is no obvious advantage in selectivity of total CLA and cis, trans-CLA compared with two commercial catalysts, what should be noticed is that the two commercial catalysts stay in low $X_{\mathrm{LA}}$ while the $X_{\mathrm{LA}}$ of $\mathrm{S} 1$ and $\mathrm{S} 4$ is up to $37.66 \%$ and $28.53 \%$ respectively. In this work, the oxidation state of $\mathrm{Ru}$ (shown in Table 2) doesn't display a significant influence on selectivity of products over isomerization of CSO.

\section{Conclusions}

In summary, a series of novel Ru/MWCNTs catalysts have been successfully prepared with the assistance of microwave heating in ethylene glycol. It has been determined that the small size of $\mathrm{Ru}$ nanoparticles are highly dispersed on the surface of mutiwalled carbon nanotubes. The TEM and TOF results revealed that higher TOF is always with higher average size of Ru NPs. The analysis of isomerization and XPS shows the redox state of $\mathrm{Ru}$ can affect isomerization reaction. Among the as-synthesized $\mathrm{Ru} /$ MWCNTs, S1 catalyst (diameter $<8 \mathrm{~nm}$, length $0.5-2 \mu \mathrm{m}$ ) and $\mathrm{S} 4$ catalyst (diameter $<8 \mathrm{~nm}$, length 10-30 $\mu \mathrm{m}$ ) exhibit excellent catalytic performance for isomerization of cottonseed oil with high yield of total CLA (15.91\% and 11.56\%, respectively) and high TOF values of 10.39 and $11.38 \mathrm{~h}^{-1}$, which is far better than two typically commercial $\mathrm{Ru}$ catalysts $\left(\mathrm{Ru} / \mathrm{Al}_{2} \mathrm{O}_{3}\right.$ and $\mathrm{Ru} / \mathrm{C})$. In addition, the isomerization catalyzed by Ru/MWCNTs keeps high selectivity of cis, trans-CLA (around 70\%) with high yield of total CLA.

\section{Conflicts of interest}

There are no conflicts to declare.

\section{Acknowledgements}

This work was financially supported by Arawana Nutrition and Safety Research Grant (O-A-1611-0018).

\section{Notes and references}

1 C. M. Alfaia, S. P. Alves, J. M. Pestana, M. S. Madeira, O. Moreira, J. Santos-Silva, R. J. B. Bessa, F. Toldra and J. A. M. Prates, Food Sci. Technol. Int., 2017, 23, 209-221.

2 S. Banni, Curr. Opin. Lipidol., 2002, 13, 261-266.

3 R. J. B. Bessa, S. P. Alves, E. Jeronimo, C. M. Alfaia, J. A. M. Prates and J. Santos-Silva, Eur. J. Lipid Sci. Technol., 2007, 109, 868-878.

4 P. Delmonte, J. A. G. Roach, M. M. Mossoba, G. Losi and M. P. Yurawecz, Lipids, 2004, 39, 185-191.

5 M. W. Pariza, Y. Park and M. E. Cook, Prog. Lipid Res., 2001, 40, 283-298.

6 N. S. Kelley, N. E. Hubbard and K. L. Erickson, J. Nutr., 2007, 137, 2599-2607.

7 C. Druart, E. M. Dewulf, P. D. Cani, A. M. Neyrinck, J. P. Thissen and N. M. Delzenne, Lipids, 2014, 49, 397-402. 8 A. Kennedy, K. Martinez, S. Chung, K. LaPoint, R. Hopkins, S. F. Schmidt, K. Andersen, S. Mandrup and M. McIntosh, J. Lipid Res., 2010, 51, 1906-1917.

9 N. M. Racine, A. C. Watras, A. L. Carrel, D. B. Allen, J. J. McVean, R. R. Clark, A. R. O'Brien, M. O'Shea, C. E. Scott and D. A. Schoeller, Am. J. Clin. Nutr., 2010, 91, 1157-1164.

10 M. Flowers and P. A. Thompson, PLoS One, 2009, 4, 9.

11 N. Castro-Webb, E. A. Ruiz-Narvaez and H. Campos, Am. J. Clin. Nutr., 2012, 96, 175-181. 
12 I. J. Onakpoya, P. P. Posadzki, L. K. Watson, L. A. Davies and E. Ernst, Eur. J. Nutr., 2012, 51, 127-134.

13 L. Rainer and C. J. Heiss, J. Am. Diet. Assoc., 2004, 104, 963968.

14 Z. Guo, G. W. Zhang and Y. Sun, Chin. J. Chem. Eng., 2003, 11, 130-135.

15 A. Philippaerts, S. Goossens, P. A. Jacobs and B. F. Sels, ChemSusChem, 2011, 4, 684-702.

16 A. Philippaerts, S. Goossens, W. Vermandel, M. Tromp, S. Turner, J. Geboers, G. Van Tendeloo, P. A. Jacobs and B. F. Sels, ChemSusChem, 2011, 4, 757-767.

17 Z. Guo and Y. Sun, Food Chem., 2007, 100, 1076-1084.

18 J. Neubronner, J. P. Schuchardt, G. Kressel, M. Merkel, C. von Schacky and A. Hahn, Eur. J. Clin. Nutr., 2011, 65, 247-254.

19 M. Kreich and P. Claus, Angew. Chem., Int. Ed., 2005, 44, 7800-7804.

20 P. Pakdeechanuan, K. O. Intarapichet, L. N. Fernando and I. U. Grun, J. Agric. Food Chem., 2005, 53, 923-927.

21 S. Liu, Z. Wang, X. Xu, Y. Ding and Z. Guo, Ind. Crops Prod., 2017, 97, 10-20.

22 A. Bernas, N. Kumar, P. Maki-Arvela, N. V. Kul'kova, B. Holmbom, T. Salmi and D. Y. Murzin, Appl. Catal., A, 2003, 245, 257-275.

23 A. Bernas, P. Maki-Arvela, N. Kumar, B. Holmbom, T. Salmi and D. Y. Murzin, Ind. Eng. Chem. Res., 2003, 42, 718-727.

24 N. Chorfa, S. Hamoudi and K. Belkacemi, Appl. Catal., A, 2010, 387, 75-86.

25 A. Bernas, P. Laukkanen, N. Kumar, P. Maki-Arvela, J. Vayrynen, E. Laine, B. Holmbom, T. Salmi and D. Y. Murzin, J. Catal., 2002, 210, 354-366.

26 O. A. Simakova, A.-R. Leino, B. Campo, P. Maki-Arvela, K. Kordas, J.-P. Mikkola and D. Y. Murzin, Catal. Today, 2010, 150, 32-36.

27 V. M. Deshpande, R. G. Gadkari, D. Mukesh and C. S. Narasimhan, J. Am. Oil Chem. Soc., 1985, 62, 734-738.

28 S. Iijima, Nature, 1991, 354, 56-58.

29 S. A. Chernyak, E. V. Suslova, A. V. Egorov, L. Lu, S. V. Savilov and V. V. Lunin, Fuel Process. Technol., 2015, 140, 267-275.
30 E. Perez-Mayoral, V. Calvino-Casilda and E. Soriano, Catal. Sci. Technol., 2016, 6, 1265-1291.

31 C. Pham-Huu, N. Keller, V. V. Roddatis, G. Mestl, R. Schlogl and M. J. Ledoux, Phys. Chem. Chem. Phys., 2002, 4, 514-521.

32 P. Serp and E. Castillejos, ChemCatChem, 2010, 2, 41-47.

33 R. M. M. Abbaslou, A. Tavassoli, J. Soltan and A. K. Dalai, Appl. Catal., A, 2009, 367, 47-52.

34 P. Serp, M. Corrias and P. Kalck, Appl. Catal., A, 2003, 253, 337-358.

35 W. X. Chen, J. Zhao, J. Y. Lee and Z. L. Liu, Mater. Chem. Phys., 2005, 91, 124-129.

36 S. Komarneni, D. S. Li, B. Newalkar, H. Katsuki and A. S. Bhalla, Langmuir, 2002, 18, 5959-5962.

37 Z. L. Liu, J. Y. Lee, W. X. Chen, M. Han and L. M. Gan, Langmuir, 2004, 20, 181-187.

38 W. Y. Yu, W. X. Tu and H. F. Liu, Langmuir, 1999, 15, 6-9.

39 B. D. Li, C. Wang, G. Q. Yi, H. Q. Lin and Y. Z. Yuan, Catal. Today, 2011, 164, 74-79.

40 E. A. Paoli, F. Masini, R. Frydendal, D. Deiana, C. Schlaup, M. Malizia, T. W. Hansen, S. Horch, I. E. L. Stephens and I. Chorkendorff, Chem. Sci., 2015, 6, 190-196.

41 B. Şen, B. Demirkan, A. Savk, R. Kartop, M. S. Nas, M. H. Alma, S. Sürdem and F. Şen, J. Mol. Liq., 2018, 268, 807-812.

42 C. Elmasides, D. I. Kondarides, W. Grunert and X. E. Verykios, J. Phys. Chem. B, 1999, 103, 5227-5239.

43 F. Salman, C. Park and R. T. K. Baker, Catal. Today, 1999, 53, 385-394.

44 F. L. Yang, J. Ren, Q. Q. Liu, L. Zhang, Y. Y. Chai and W. L. Dai, J. Energy Chem., 2019, 33, 1-8.

45 Y. X. Wang, S. Aghamohammadi, D. Y. Li, K. Z. Li and R. Farrauto, Appl. Catal., B, 2019, 244, 438-447.

46 L. M. Zhu, Z. H. Wang, L. Wang, L. L. Xie, J. J. Li and X. Y. Cao, Chem. Eng. J., 2019, 364, 503-513.

47 Q. Guo, F. He, Q. Li, Z. Deng, J. Jin and Y. Ha, Food Control, 2016, 67, 255-264.

48 M. Q. Xu, S. S. Wang, L. N. Li, J. Gao and Y. W. Zhang, Catalysts, 2018, 8, 460-479. 